\title{
Nuevas utopías en el contexto de la globalización
}

\author{
Reseña de: Harvey, David (2000), Spaces of hope, California \\ University Press, U.S.A, 293 PP.
}

Lo que el geógrafo y urbanista David Harvey plantea en Spaces of Hope (2000) -aún sin traducción al castellano-, es un análisis de diversas problemáticas que el fenómeno de la globalización presenta en la actualidad y se suma a una búsqueda de viejos espacios que se encuentran en el cuerpo de los individuos y en el cuerpo social, como parte importante de la sociedad.

Su enfoque marxista le lleva a plantear que las transformaciones espaciales y territoriales de los últimos 15 años se encuentran vinculadas, en gran medida, con la lucha de clases y una nueva expansión de la acumulación del capital; que la visión de Marx y Engels, aunque precaria en el sentido espacial, continúa marcando trayectorias de análisis en un sentido muy similar a los tiempos en que realizaron sus observaciones.

Espacios de esperanza (2000) es un conjunto de ensayos ubicados en el análisis espacial de la vieja guardia marxista, que repiensa la problemática social en el contexto de la globalización. Lo hace mediante argumentos basados en la dialéctica materialista, en los que la trayectoria del pensamiento del autor presenta al espacio como categoría, desde una perspectiva que rescata la factibilidad del reencuentro de las minorías con sus espacios de praxis.

\section{Una semblanza histórica}

Si revisamos la historia de los años setenta, en una minoría radical -por lo menos en las universidades y sindicatos- se vivió un gran entusiasmo político que algunos actores sociales de la época ahora llaman la esperanza en la utopía, esperanza de realizar cambios radicales en la sociedad. La participación era entendida como un acto político, y en este clima hubo movimientos de protesta alrededor del mundo, tanto más de índole social y política que, por un lado, reconocían la fatiga y desgaste del modelo económico desarrollista y por otro, en el clima de la 'guerra fría' buscaban la implantación del socialismo. 
En los años setenta la emergencia del macartismo inhibió la lectura de textos marxistas, e incluso fue necesario 'disfrazar' la lectura de Das Kapital como cursos independientes. No obstante, según apunta Harvey "debía tener algo importante que decir; de otra manera, no habría sido suprimido su lectura por tanto tiempo" (p. 3). Sin duda, esta situación ha cambiado y este curso se da como parte de la academia regular, aunque clasificando a Marx como un economista posricardiano.

Aun antes de la caída del muro de Berlín, el marxismo se había excluido de la academia y la moda política. A decir de Harvey, "el marxismo tradicional fue sistemáticamente denigrado y criticado como insuficientemente vinculado a cuestiones más importantes como el género, raza, sexualidad, religión, etnicidad, dominio colonial, ambiente, etc" (p. 5). Como modo de pensar, el marxismo fue inherentemente antagónico hacia dichas formulaciones alternativas y por lo tanto, se le consideró una causa perdida.

Ante este diagnóstico, Harvey encuentra que, paradójicamente, hoy es más fácil conectar los análisis de Marx a la vida cotidiana y resulta más pertinente su lectura en círculos menos radicales de lo que fue en los setenta. Hoy en cambio, "en las condiciones y significados en los que se vive en las ciudades, los individuos parecen atrapados, indefensos, prisioneros y fragmentados dentro de una red de vida urbana que ha sido construida por agentes del poder que parecen encontrarse muy lejanos" (p. 9).

Más aun, Harvey asume que Marx bien puede ser considerado como un posmoderno si se ve su obra como un trabajo de desconstrucción de los principios del capitalismo.

Teniendo eso en mente, Harvey gira hacia dos tópicos basado en dos términos: 'la globalización' y ‘el cuerpo'. El primero era poco conocido antes de mediados de los años 70, pero se convirtió en el emblema del nuevo esquema mundializado y neoliberal desplazando conceptos de gran carga política como el imperialismo y el colonialismo. Así, la globalización se difundió ampliamente en la literatura financiera como mecanismo legitimador de la reestructuración económica y productiva, así como herramienta deslegitimadora de los movimientos sindicales nacionales y locales.

El segundo término que aborda Harvey: 'el cuerpo', entró en el debate debido a las consideraciones del feminismo de la segunda ola acerca del género, sexualidad y el poder del orden simbólico y a través del movimiento postestructuralista en gene- 
ral, y la desconstrucción en particular. El efecto de este debate fue la pérdida de confianza en todas las categorías establecidas anteriormente para entender el mundo.

La convergencia de estos dos movimientos ha reenfocado la atención del autor sobre 'el cuerpo' como la base para entender a ciertos círculos, como el sitio privilegiado de la resistencia política y la política emancipatoria. Si como muchos argumentan, el cuerpo es un constructo social, entonces no puede ser entendido fuera de las fuerzas que lo construyen y lo envuelven.

\section{El manifiesto comunista}

La relectura de Harvey acerca del 'texto dirigido a los obreros del mundo', en el marco de lo que se ve en las relaciones laborales de la actualidad, puede sorprender a los escépticos. Todas las profesiones se han convertido en relaciones de trabajo asalariadas, desde el médico hasta el poeta. "Todo lo sólido se desvanece en el aire".

El Manifiesto Comunista advierte sobre la inevitabilidad de las crisis caracterizadas por la absurda 'sobreproducción' en medio de necesidades sociales no resueltas, del hambre en medio de la abundancia y cómo se profundizarán y ampliarán en cada ciclo. Su escrutinio más cercano habla de cómo la burguesía crea, así como también destruye las fundaciones geográficas -ecológicas, espaciales y culturales- de sus propias actividades construyendo un mundo a su propia imagen y medida.

Dichas diferencias son incluso más importantes hoy de lo que fueron en tiempo de sus autores, por lo que Harvey afirma que "Las debilidades de El Manifiesto y sus fortalezas necesitan ser confrontadas y redireccionadas" (p. 23).

Marx y Engels tomaron el problema del desarrollo desigual y el establecimiento del espacio como algo ambivalente. Por un lado, a las cuestiones de urbanización, transformación geográfica y globalización se les da un lugar prominente en sus argumentaciones, pero por otro, las ramificaciones potenciales de la reestructuración geográfica tienden a perderse en la retórica, lo que privilegia al tiempo y la historia sobre el espacio y la geografía. Aunque el documento es muy eurocentrista, la importancia de lo global no es ignorada.

La acumulación del capital ha estado siempre vinculada a la geografía. Sin expansión geográfica, el capitalismo es impensable y ya hubiera sucumbido; sin la reorganización espacial y el 
desarrollo desigual, habría dejado de funcionar como sistema económico-político. Por medio de la geografía, la burguesía llegó al poder y confirmó su misión revolucionaria, en parte, por medio de las transformaciones geográficas internas y externas.

Comenzó la nueva historia de las ciudades; la rápida urbanización dominó al campo; se concentraron las fuerzas productivas y la fuerza laboral en un espacio con la consecuente concentración masiva del poder político y económico. También comenzaron a construirse instituciones como los sindicatos para articular los reclamos generados ante esta situación.

La organización de las luchas obreras se concentró y difundió a través del espacio de manera que reflejó las acciones del capital. Marx y Engels describieron el carácter cosmopolita de la producción como "las creaciones intelectuales de naciones individuales que se convierten en propiedad común" (p. 25). Esto puede considerarse como una descripción de la 'globalización' como la conocemos. Redimensionando, puede afirmarse que la lucha de clases se volvió universal.

Es vital reconocer que el desarrollo geográfico desigual, así como la reestructuración geográfica han sido preeminentes en la acumulación del capital y que la lucha de clases descubre las diferencias de este terreno tan diverso, cuestión que el socialismo debió reconocer como la diversidad geográfica y geopolítica. Ya Lefebvre ha remarcado que el capitalismo ha sobrevivido desde el siglo XV por un único medio: ocupando y reproduciendo espacio.

Harvey apunta que el imperativo para los trabajadores es reunirse, pero ahora las barreras son más difíciles:

- La fuerza de trabajo se encuentra más dispersa geográficamente;

- Culturalmente es más heterogénea;

- Étnica y religiosamente más diversa;

- Racialmente más estratificada;

- Lingüísticamente fragmentada.

El efecto esperado es diferenciar de manera radical los modos de resistencia al capitalismo y la definición de alternativas. Los medios de comunicación y las oportunidades de traslado han mejorado, pero ello significa muy poco para quien vive con menos de un dólar al día.

Las disparidades geográficas y sociales en salarios y previsión social dentro de la clase trabajadora global son igualmente 
más grandes. Hoy existen las mismas brechas entre los trabajadores de Alemania y Estados Unidos y los asalariados más pobres de Indonesia y Malí que las que existían entre la aristocracia y su contraparte del siglo XIX. Además, la participación de la mujer está más generalizada y más concentrada en ciertas categorías carentes de capacitación.

¿Cómo configurar lo ambiental con lo económico, lo político con lo cultural? es más difícil en el ámbito global, donde los supuestos de homogeneidad de valores y aspiraciones no pueden sostenerse. Como la población global está en movimiento parece imposible detener los flujos migratorios. En este sentido, la población global se ha desplazado y "resulta más fácil organizar la lucha de clases en las pequeñas villas mineras de Gales que en Sao Paulo, Bombay o Los Ángeles” (p. 46) donde las tasas de explotación se ven incrementadas por la mano de obra infantil y femenina y las grandes multinacionales subcontratan el trabajo para no aparecer como explotadoras.

Hasta que la clase trabajadora aprenda cómo confrontar al poder de la burguesía para mandar y producir espacio para dar forma a una nueva geografía (de la producción y de las relaciones sociales) siempre jugará desde una posición de debilidad.

Harvey plantea la necesidad de revitalizar la vanguardia socialista mediante un movimiento internacional que sea capaz de resumir, de manera apropiada, el descontento que deriva del ejercicio desnudo del poder que persigue la utopía neoliberal. El punto de inicio de la lucha de clases yace en el cuerpo laboral de los billones de trabajadores explotados.

\section{La globalización contemporánea}

¿Por qué la palabra globalización ha entrado en nuestro discurso de esa forma? Aún entre los progresistas o izquierdistas en el mundo capitalista palabras más cargadas políticamente han sido sustituidas paulatinamente por este término.

¿Cómo ha sido usado políticamente este concepto? Puede decirse que de 1492 en adelante, la internacionalización del comercio se puso en marcha. El capitalismo no podía construirse sin 'espacios fijos', de modo que construyó sus espacios geográficos con infraestructura y comunicaciones solamente para destruirlos y reconstruirlos en otra fase de su desarrollo.

Es muy probable que sólo se trate de una nueva fase en la que el capital está buscando nuevos espacios para su reproduc- 
ción. Para Lenin y Rosa Luxemburgo fue difícil entender cómo la producción de espacio era fundamental e integral para la dinámica de la acumulación de capital y a la geopolítica de la lucha de clases.

Harvey trata de atraernos a la idea de un 'materialismo histórico-geográfico' con el fin de prepararnos a mirar con mayor flexibilidad la importancia de procesos como la globalización y el desarrollo geográfico desigual. Tenemos que reconocer la dimensión geográfica y el asentamiento de la lucha de clases.

La importancia de que la estructura de clase, la conciencia de clase y la clase política se construyen de manera muy diferente otorgando mayor importancia a las diferencias geográficas dentro de una nación, es más grande de lo que se ha querido reconocer.

La idea de una revolución informática es muy poderosa y es vista como "el amanecer de una nueva era de globalización dentro de una sociedad en la cual la información será el reino supremo" (p. 62). No se ha tomado en cuenta que la nueva tecnología también es inherentemente emancipatoria. Cuando en la historia del proceso de globalización se escriba el costo del espacio resultante, la revolución informacional se verá más significativa de lo que parece.

\section{El derecho a un desarrollo desigual}

En enero de 1996, el Ejército Zapatista de Liberación Nacional (EZLN) lanzó un llamado a la reunión mundial contra el neoliberalismo y por la humanidad. Proponían una serie de reuniones en oposición al capitalismo neoliberal y en pro de la internacionalización de la esperanza. Movimientos como este los hay en otras partes del mundo, como en Nepal y en Brasil, y aparecen como alternativas al capitalismo homogeneizador y globalizante. El caso de los zapatistas ha fascinado a la izquierda por una variedad de buenas y malas razones: le han dado prominencia al uso del Internet y han insistido en "la comunalidad de las causas que se encuentran detrás de los infortunios contra los cuales se rebelan" (p. 74) el lado negativo, ha sido incuestionablemente caracterizado por una marginalidad 'romántica' de una supuesta 'otredad auténtica' fuera de todas las formas de globalización.

Estos movimientos aparecen como los 'auténticos' portadores de una 'verdad' alternativa para homogeneizar y globalizar el capitalismo. De manera inversa, la habilidad de los zapatistas 
para transformar lo que es una lucha local con temáticas particulares en un fenómeno a una escala analítica y política completamente diferente es lo que lo hace tan visible y políticamente interesante.

Derivado de los análisis anteriores, Harvey hace tres propuestas:

- Restaurar viejos valores (religiosos, culturales, solidaridades, etcétera);

- Perseguir una visión utópica de alguna clase de comunitarismo;

- La integración de formas culturales locales pero también aceptar ciertas normas y formas de 'hacer negocios' y la 'libertad de escoger'.

En este sentido, el derecho a un desarrollo geográfico desigual, a construir diferentes formas de asociación humana caracterizadas por diferentes leyes, reglas y costumbres en una variedad de escalas aparece en estas consideraciones como un derecho humano fundamental como cualquier otro.

Se presume que una dialéctica es capaz de dirigir la dinámica espacio temporal abierta y directamente, y también de representar múltiples procesos materiales intersectados que nos aprisionan en las redes de la vida socioecológica contemporánea.

De esta manera, se puede construir un espacio para experimentar con el pensamiento, si bien existe el peligro de que esto pudiera degenerar en la producción de sueños irrealizables, debemos asumir que el materialismo histórico geográfico debería ayudar a que esos sueños se conviertan en prospectos realmente interesantes.

Para que ello suceda, Harvey toma la figura del "architect", arquitecto o urbanista insurgente, porque él da forma a los espacios con el fin de otorgarles utilidad social y humana, al tiempo que les asigna significados simbólico/estéticos; lucha por abrir espacios a nuevas posibilidades para formas futuras de vida social.

En este sentido, el poder del capitalismo como sistema social descansa en su capacidad de movilizar el imaginario de los empresarios, financieros, artistas, arquitectos y aún los planificadores urbanos y burócratas para comprometerlos en las actividades materiales que mantienen al sistema reproduciéndose.

El arquitecto aparece como una parte de la rueda de la urbanización capitalista -construido y constructor de ese proceso-, actúa de acuerdo con un papel socialmente construido mien- 
tras confronta las circunstancias y conciencia que derivan de la vida diaria, donde existen expectativas y donde las habilidades adquiridas y supuestas se usan en forma limitada para los propósitos definidos usualmente por otros.

Pero el arquitecto insurgente como cualquier otra persona tiene un cuerpo que ocupa un espacio exclusivo por un cierto tiempo. La persona está dotada de ciertos poderes y habilidades que puede usar para cambiar el mundo. Nadie puede desear cambiar el mundo sin cambiarse él mismo.

Pero esto no quiere decir que "las transformaciones personales son suficientes para que ocurra el cambio social" (p. 235). Nadie puede cambiar el mundo solo. Para ello se hace necesaria una suerte de colectivización del impulso y el deseo de cambio. Podemos aspirar a ser agentes subversivos, una quinta columna dentro del sistema con un pie plantado firmemente en algún campo alternativo.

"La mayoría de las políticas y formas colectivas de acción preservan y sustentan el sistema existente aun cuando profundicen en sus contradicciones internas, ecológicas, políticas y económicas" (p. 239). El comunitarismo como movimiento utópico da precedencia a la ciudadanía, a la identificación colectiva sobre la ventaja individual. También es preciso reconocer que la comunidad por sí misma, invariablemente degenera en exclusiones regresivas y fragmentaciones.

Dichos 'arquitectos' deben encontrar medios para dar forma a un cambio historicogeográfico más integrado, más allá de los límites definidos típicamente por alguna socialidad de interés común. Deben ser capaces de traducir las aspiraciones políticas a través de una enorme variedad de condiciones políticas, sociales y económicas.

El momento de universalidad no es "el momento final de revelación de la verdad absoluta sino un momento de decisión existencial, un momento de praxis, cuando ciertos principios se materializan a través de la acción en el mundo" (p. 246).

En medio de estas reflexiones es importante 'exhumar' las rutas de los principios universales expresados en lo que lo personal es y puede ser político. Paradójicamente, nos encontramos en el momento de buscar la creación de un discurso acerca de lo correcto o equívoco, acerca de imperativos morales y medios propios e impropios, y fines a través de los cuales persuadirnos, tanto como a los demás, de ciertas líneas consistentes de acción sabiendo que cada uno de nosotros es diferente y que ninguna 
particularidad es exactamente la misma que otra. Para esta búsqueda el autor plantea una lista de derechos:

1. El derecho a las oportunidades de la vida;

2. El derecho a la asociación política y 'buena' gobernancia;

3. Los derechos de los trabajadores directos en el proceso de producción;

4. El derecho a la inviolabilidad e integridad del cuerpo humano;

5. Derecho de inmunidad/desestabilización;

6. El derecho a un ambiente saludable y decente para vivir;

7. El derecho al control colectivo de los recursos en propiedad común;

8. Los derechos de aquellos que ya nacieron;

9. El derecho a la producción de espacio;

10. El derecho a la diferencia, incluyendo aquella de un desarrollo geográfico desigual;

11. Nuestros derechos como seres especie.

El utopismo dialéctico al que aspira Harvey requiere de la perspectiva de una revolución histórico-geográfica larga y permanente, pero las aspiraciones deben ser atemperadas por un sentido de las limitaciones y de vulnerabilidad de cada sociedad.

Las esperanzas de Harvey de construir un mundo de respetable igualdad, no sólo de talentos y logros sino de condiciones y oportunidades de vida, son expuestas en el Apéndice del texto que se reseña, el cual, desde mi perspectiva, observa y propone nuevas formas de organización social que requieren ser recuperadas, transformadas y/o construidas para una mejor convivencia social.

Diana Bailleres

El Colegio Mexiquense, A.C. correo-e: dbailleres@cmq.edu.mx 